\title{
Direct Torque Control of PMSM using Space Vector Modulation
}

\author{
T. Rama Sastry ${ }^{1}$, S. Harish ${ }^{1}$, M.Sudheer Kumar ${ }^{1}$ \\ Assistant Professor, Electrical \& Electronics Engineering, ANITS, Visakhapatnam, India ${ }^{1}$
}

\begin{abstract}
The direct torque control of permanent magnet synchronous motor using space vector pulse width modulation technique and fuzzy controller is presented in this paper. It is compared with the conventional DTC. In PMSM the electromagnetic torque is directly proportional to the angle between stator and rotor flux linkages. This angle can be controlled by controlling the stator flux linkages. The stator flux linkages can be controlled by controlling the stator voltage vector, which can be controlled by controlling the switching frequency of the inverter. The DTCSVM and DTC-Fuzzy controller is implemented in MATLAB / simulation.
\end{abstract}

Keywords: DTC, SVM, Fuzzy, PMSM

\section{INTRODUCTION}

The main features of the PMSM are High torque / weight ratio, and negligible maintenance. The advances in the recent technology improve the magnetic and thermal capabilities of permanent magnet material, so that it is possible to design permanent magnets with high residual flux densities.

The direct torque control scheme is first proposed for induction motor [1] and it is next implemented to the synchronous motor [4]. The difference between DTC and vector control is, the later involves the current controller and park's transformation, whereas in DTC there is no need of axis of transformation and current control. The DTC scheme is simple, robust control technique and gives fast dynamic response.

However DTC suffers from variable switching frequency, violation of polarity consistency rules and high ripples in the torque and current due to sector changes. All the above difficulties can be eliminated by employing the voltage modulator with predictive controller, in which the torque error, flux reference, stator flux vector $\left(\lambda_{S}\right)$, position of the stator flux and current vector $\left(i_{d q}\right)$ are the inputs for the predictive controller. The predictive controller determines the stator voltage and its phase, which are the inputs for the space vector voltage modulator. It generates the necessary switching pulses for the inverter.

Also, fuzzy logic controller has been used instead of PI controller with DTC-SVM to reduce the ripple content in the current, Torque and flux.A complete simulation of the DTC-SVM with PI controller and with fuzzy controller fed to PMSM is tested using MATLAB / SimuLink.

\section{MODEL OF PMSM}

The voltage and flux equations for a PMSM in the rotor oriented coordinates $\mathrm{d}-\mathrm{q}$ can be expressed as:

$$
\begin{aligned}
& \mathrm{V}_{\mathrm{ds}}=\mathrm{R}_{\mathrm{S}} \mathrm{i}_{\mathrm{ds}}+\rho \lambda_{\mathrm{ds}}-\mathrm{p} \omega_{\mathrm{m}} \lambda_{\mathrm{qs}} \\
& \mathrm{V}_{\mathrm{qs}}=\mathrm{R}_{\mathrm{S}} \mathrm{i}_{\mathrm{qs}}+\rho \lambda \mathrm{q}_{\mathrm{s}}+\mathrm{p} \omega_{\mathrm{m}} \lambda_{\mathrm{ds}} \\
& \lambda_{\mathrm{ds}}=\mathrm{L}_{\mathrm{d}} \mathrm{i}_{\mathrm{ds}}+\lambda_{\mathrm{PM}} \\
& \lambda_{\mathrm{qs}}=\mathrm{L}_{\mathrm{d}} \mathrm{i}_{\mathrm{qs}}
\end{aligned}
$$

and the electromagnetic torque equation

$$
\mathrm{T}_{\mathrm{e}}=1.5 \mathrm{p}\left[\lambda_{\mathrm{ds}} \mathrm{i}_{\mathrm{qs}}-\lambda_{\mathrm{qs}} \mathrm{i}_{\mathrm{ds}}\right]=1.5 \mathrm{p}\left[\lambda_{\mathrm{PM}} \mathrm{i}_{\mathrm{qs}}-\left(\mathrm{L}_{\mathrm{d}}-\mathrm{L}_{\mathrm{q}}\right) \mathrm{i}_{\mathrm{qs}}\right.
$$

where $\rho$ is the differential operator, $p$ is the number pair of poles, $R_{S}$ is the stator winding resistance, $\omega_{\mathrm{m}}$ is the angular frequency, $\mathrm{V}_{\mathrm{ds}}, \mathrm{V}_{\mathrm{qs}}$ and $\mathrm{i}_{\mathrm{ds}}, \mathrm{i}_{\mathrm{qs}}$ are $\mathrm{d}, \mathrm{q}$ components of voltage and current, $\lambda_{\mathrm{ds}}, \lambda_{\mathrm{qs}}$ are $\mathrm{d}, \mathrm{q}$ components of the stator flux linkage, $L_{d}, L_{q}$ are $d, q$ axis inductances, and $\lambda_{\mathrm{PM}}$ is the permanent magnet rotor flux linkage. The dynamics of motion equation is given by

$$
\rho \omega_{\mathrm{m}}=(1 / \mathrm{J}) *\left(\mathrm{~T}_{\mathrm{e}}-\mathrm{T}_{1}-\mathrm{k} \omega_{\mathrm{m}}\right)
$$

where $\mathrm{J}$ is the moment of inertia, $\mathrm{T}_{1}$ motor torque and $\mathrm{k}$ is the damping constant. The phasor diagrams of the PMSM are shown in figures (1a), (1b), (1c).

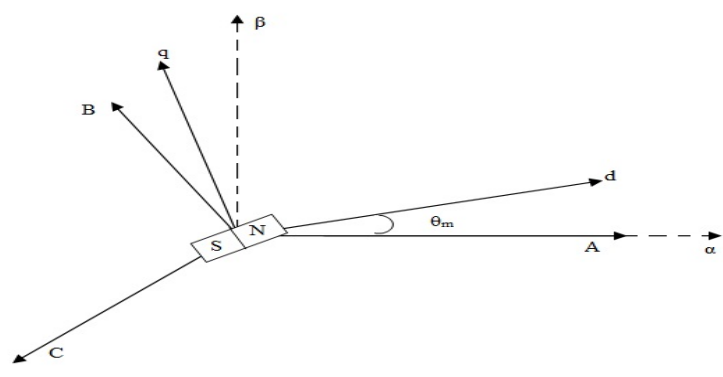

a: Different coordinates of PMSM

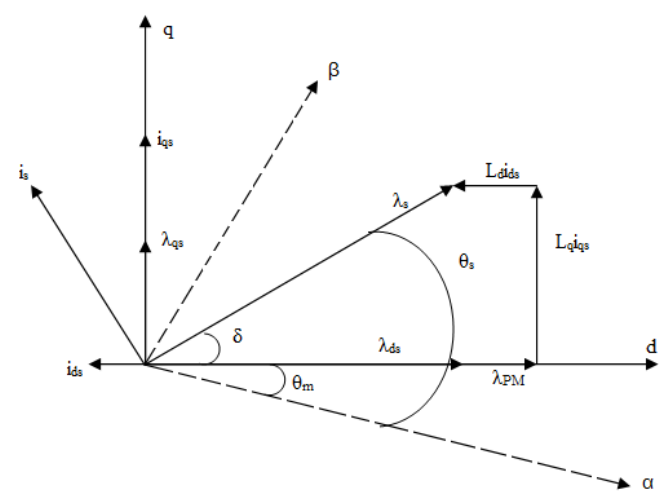

b: Flux and Voltage vectors 


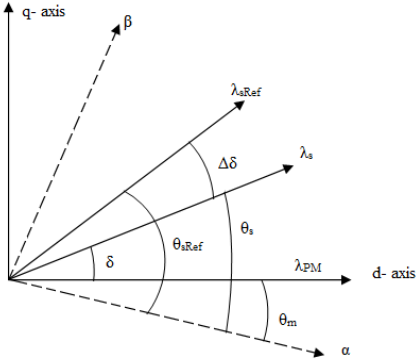

c:Vector diagram of illustrating torque control conditions Fig 1: Phasor diagrams of PMSM

\section{III.DIRECT TORQUE CONTROL - SPACE VECTOR MODULATION (DTC-SVM)}

A predictive controller is used for which the torque error signal $\left(e \mathrm{~T}_{\mathrm{e}}\right)$ and reference stator flux $\left(\lambda_{\mathrm{sRef}}\right)$, position of stator flux vector $\left(\theta_{\mathrm{s}}\right)$, and measured current are the inputs and the outputs of it are the stator voltage and its phase ( $\left.\mathrm{V}_{\text {Ref }}=\left[\mathrm{V}_{\mathrm{Ref}}, \varphi_{\mathrm{Ref}}\right]\right)$. These are the inputs for the space vector voltage modulator, which generates the switching pulses $S_{\mathrm{A}}, \mathrm{S}_{\mathrm{B}}, \mathrm{S}_{\mathrm{C}}$ for the inverter.

Sampled torque error $\left(\mathrm{eT}_{\mathrm{e}}\right)$ and reference stator flux amplitude $\left(\lambda_{\text {sRef }}\right)$ are delivered to the predictive controller. The relation between error of torque and increment of load angle $\Delta \delta$ is non linear. Therefore PI controller, which generates the load angle increment, required minimizing the instantaneous error between reference torque and actual torque has been applied. The reference values of the stator voltage vector $v_{\text {Ref }}=\left[\mathrm{V}_{\text {Ref }}, \varphi_{\text {Ref }}\right]$ is calculated based on stator resistance $R_{s}, \Delta \delta$ signal, actual stator current vector $i_{S}$, actual stator flux amplitude $\lambda_{\mathrm{S}}$ and position $\theta_{\mathrm{S}}$ as follows

$$
\begin{aligned}
& \mathrm{V}_{\text {Ref }}=\left(\mathrm{v}_{\text {SaRef }}{ }^{2}+\mathrm{v}_{\mathrm{S} \beta \operatorname{Ref}}{ }^{2}\right)^{0.5}, \varphi_{\text {Ref }}=\arctan \left(\mathrm{v}_{\mathrm{S} \beta \text { Ref }} / \mathrm{v}_{\text {SaRef }}\right) \\
& \text { ( } 7 \text { ) } \\
& \mathrm{v}_{\mathrm{S} \beta \mathrm{Ref}}=\left\{\left(\lambda_{\mathrm{Sref}} \sin \left(\theta_{\mathrm{s} \alpha}+\Delta \delta\right)-\lambda_{\mathrm{S}} \sin \theta_{\mathrm{s}}\right) / \mathrm{T}_{\mathrm{s}}\right\}+\mathrm{R}_{\mathrm{S}} \mathrm{i}_{\mathrm{s} \beta}(9)
\end{aligned}
$$

and $\mathrm{T}_{\mathrm{s}}$ is the sampling time.

For constant flux operating region, the reference value of stator flux amplitude $\lambda_{\text {sRef }}$ is equal to the flux amplitude produced by permanent magnet $\lambda_{\mathrm{PM}}$.

The block diagram of the DTC-SVM controlled PMSM is shown in fig (2).

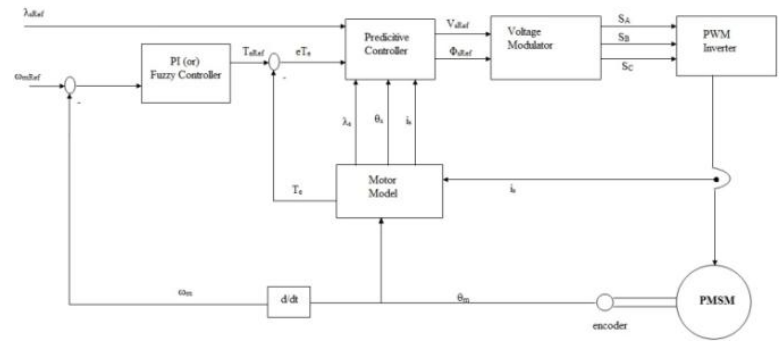

Fig 2: Block diagram of the DTC-SVM controlled PMSM

\section{IV.FuZZY CONTROLLER}

The Fuzzy logic controller (FLC) uses a set of fuzzy rules representing a control decision mechanism to adjust the effect of certain system stimuli. Therefore, the aim of using FLC is to replace a skilled human operator with a fuzzy rules-based system. The fuzzy input vectors are the motor speed deviation $\Delta \omega$ and the acceleration $\Delta \omega$. The fuzzy set for inputs and output membership functions are shown in Fig. (4). Seven linguistic variables $(L V)$ are used for each input variables. These are PL (Positive Large), PM (Positive Medium), PS (Positive Small), Z (Zero), NS (Negative Small), NM (Negative Medium) and NL (Negative Large). The fuzzy output is the change in reference torque ( $\Delta$ Tref $\{k\})$ which is to be added to the previous value of reference torque $(\operatorname{Tr} e f\{k-1\})$. The output fuzzy sets have the same linguistic variables used for input except $\mathrm{T}$ is added to indicate the fuzzy sets are used for torque. For example T-PL means Torque Positive Large. A look-up table given in table 1 , in which the relation between the input variables, $\Delta \omega$ and $\Delta \omega$, are defined and the output variable of the fuzzy logic controller was developed and used in the simulation. The maximum of minimum method has been used to find the output fuzzy rules stage, as

\section{$\Delta \mathrm{T}(\mathrm{K})=\left(\int \mathrm{y} * \mu(\mathrm{y}) * \mathrm{dy}\right) /\left(\int \mu(\mathrm{y}) * \mathrm{dy}\right.$}

The fuzzy logic controller is implemented and simulated to determine the desired torque reference $\left(T_{\text {Ref }}\right)$ for the system shown in fig 3 . The FLC output is added to the previous torque reference $T_{\text {Ref }}(k-1)$ to calculate the present $\mathrm{T}_{\text {Ref }}(\mathrm{k})$ by using the following equation.

$\mathrm{T}_{\mathrm{Ref}}(\mathrm{K})=\mathrm{T}_{\mathrm{Ref}}(\mathrm{K}-1)-\Delta \mathrm{T}(\mathrm{K})$

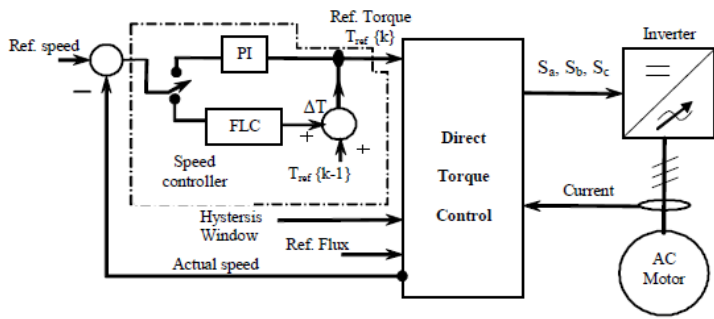

Fig 3: DTC System with PI and FLC for speed loop

Table 1 : Look-up Table which defines the relationshipbetween input and output variable in a fuzzy

\begin{tabular}{|c|l|l|l|l|l|l|l|}
\hline \multirow{2}{*}{$\begin{array}{l}\text { Speed } \\
\begin{array}{l}\text { Change } \\
\Delta \omega)\end{array}\end{array}$} & \multicolumn{6}{|c|}{ Speed Deviation Change $\left(\Delta \omega^{\prime}\right)$} \\
\cline { 2 - 8 } & NL & NM & NS & Z & PS & PM & PL \\
\hline NL & T-NL & $\begin{array}{l}\text { T- } \\
\text { NL }\end{array}$ & $\begin{array}{l}\text { T- } \\
\text { NL }\end{array}$ & $\begin{array}{l}\text { T- } \\
\text { NL }\end{array}$ & $\begin{array}{l}\text { T- } \\
\text { NM }\end{array}$ & $\begin{array}{l}\text { T- } \\
\text { NS }\end{array}$ & $\begin{array}{l}\text { T- } \\
\text { Z }\end{array}$ \\
\hline NM & T-NL & $\begin{array}{l}\text { T- } \\
\text { NL }\end{array}$ & $\begin{array}{l}\text { T- } \\
\text { NL }\end{array}$ & $\begin{array}{l}\text { T- } \\
\text { NM }\end{array}$ & $\begin{array}{l}\text { T- } \\
\text { NS }\end{array}$ & $\begin{array}{l}\text { T- } \\
\text { NS }\end{array}$ & $\begin{array}{l}\text { T- } \\
\text { NS }\end{array}$ \\
\hline NS & T-NL & $\begin{array}{l}\text { T- } \\
\text { NL }\end{array}$ & $\begin{array}{l}\text { T- } \\
\text { NM }\end{array}$ & $\begin{array}{l}\text { T- } \\
\text { NS }\end{array}$ & $\begin{array}{l}\text { T- } \\
\text { NS }\end{array}$ & $\begin{array}{l}\text { T- } \\
\text { NS }\end{array}$ & $\begin{array}{l}\text { T- } \\
\text { NS }\end{array}$ \\
\hline Z & T-NM & $\begin{array}{l}\text { T- } \\
\text { NM }\end{array}$ & $\begin{array}{l}\text { T- } \\
\text { NS }\end{array}$ & T-Z & $\begin{array}{l}\text { T- } \\
\text { PS }\end{array}$ & $\begin{array}{l}\text { T- } \\
\text { PM }\end{array}$ & $\begin{array}{l}\text { T- } \\
\text { PL }\end{array}$ \\
\hline PS & T-PM & $\begin{array}{l}\text { T- } \\
\text { PM }\end{array}$ & $\begin{array}{l}\text { T- } \\
\text { PM }\end{array}$ & $\begin{array}{l}\text { T- } \\
\text { PM }\end{array}$ & $\begin{array}{l}\text { T- } \\
\text { PM }\end{array}$ & $\begin{array}{l}\text { T- } \\
\text { PL }\end{array}$ & $\begin{array}{l}\text { T- } \\
\text { PL }\end{array}$ \\
\hline PM & T-NS & T-Z & T- & T- & T- & T- & T- \\
\hline PL & T-Z & T- & T- & T- & T- & T- & T- \\
\hline
\end{tabular}


set form.

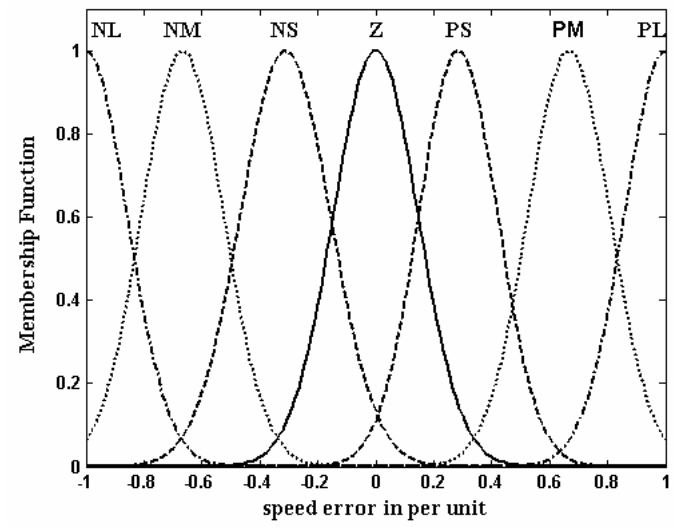

a: Input fuzzy set (speed error in p.u.)

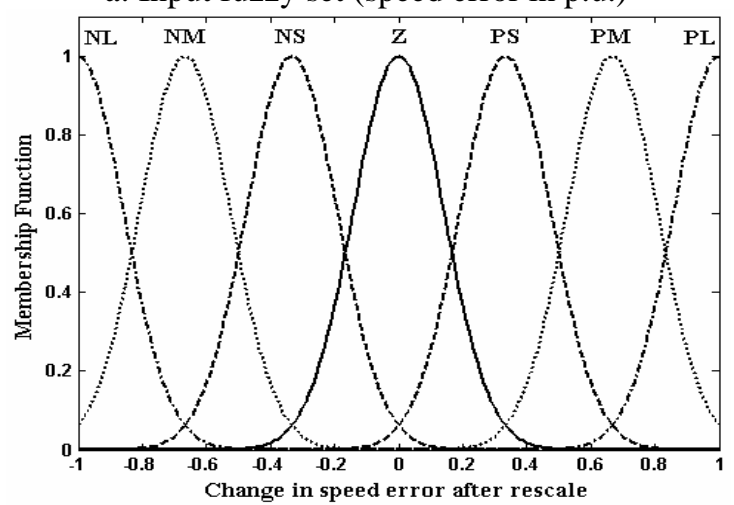

b: Input fuzzy set (change in speed error.)

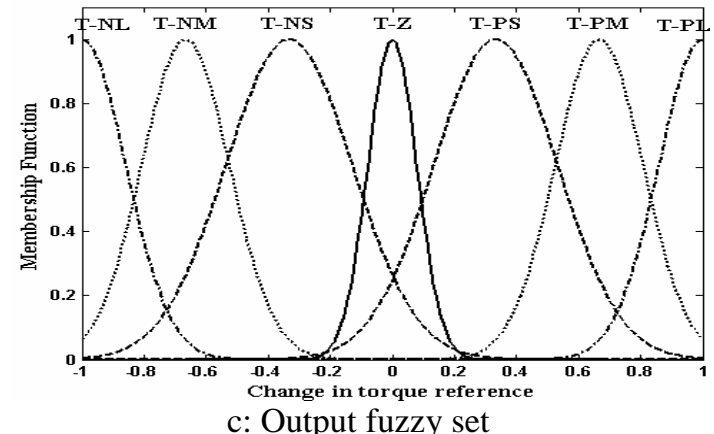

Fig 4:Input and Output Fuzzy Memberships The output surface of the FLC is shown in figure (5).

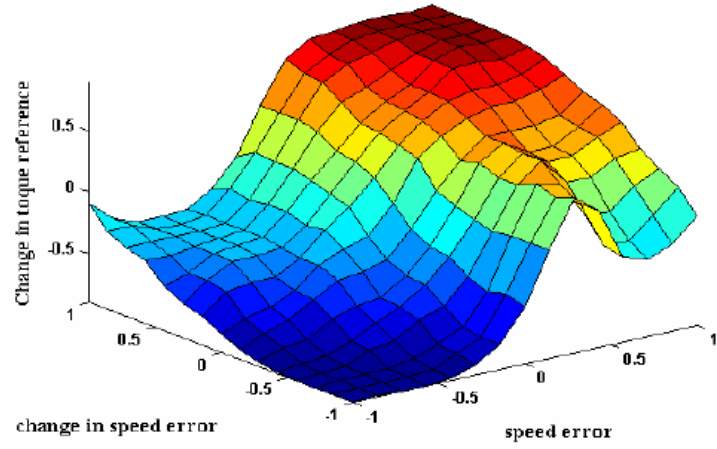

Fig 5: Output surface of FLC

\section{SIMULATION RESULTS}

The simulation results of the DTC - SVM fed PMSM are shown below. The torque tracking response is shown in fig $6 a, 6 b$. The flux tracking response is shown in fig $7 \mathrm{a}, 7 \mathrm{~b}$.
The torque ripple is shown in torque response alone in fig $8 \mathrm{a}, 8 \mathrm{~b}$.

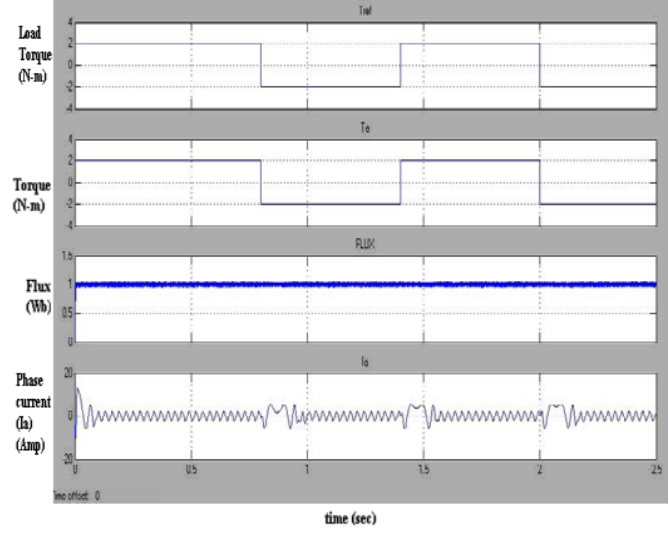

Fig. 6a Torque Tracking Response with PI controller

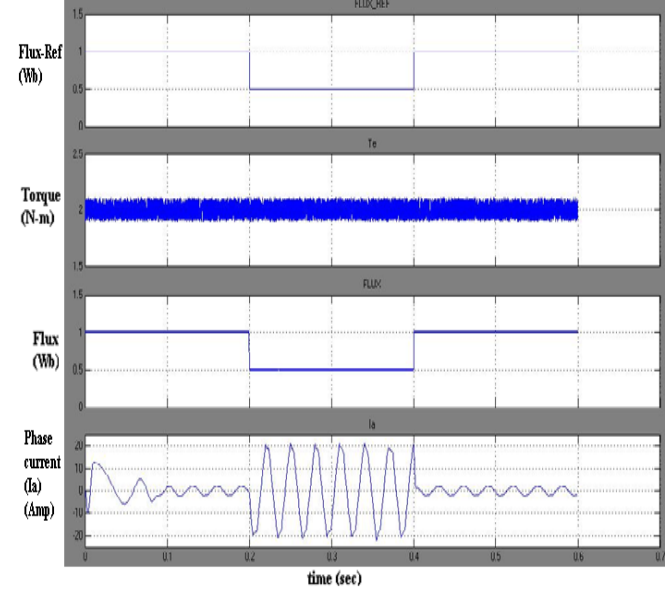

Fig.6b Torque Tracking Response with Fuzzy controller

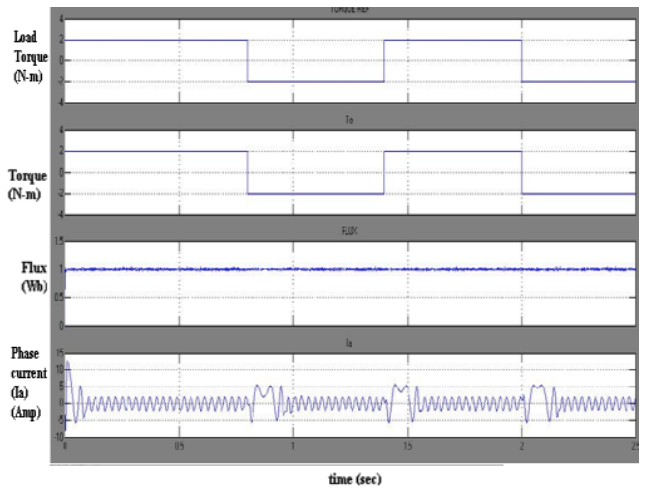

Fig. 7a Flux Tracking response with PI controller

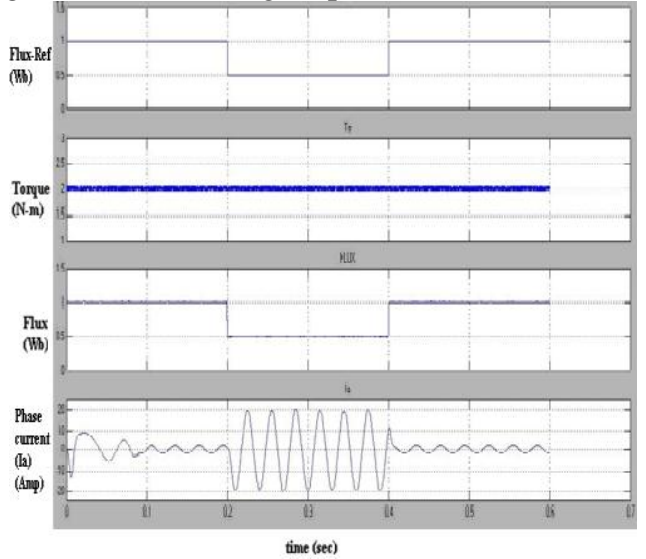

Fig. 7b Flux Tracking response with Fuzzy controller 


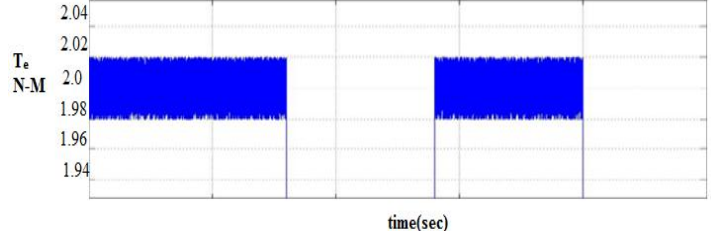

Fig. 8a Torque response with PI controller

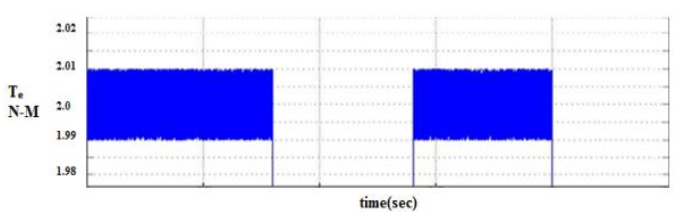

Fig. 8bTorque responsewith Fuzzy controller

\section{CONCLUSION}

From the paper the following conclusions are made DTC - SVM with PI controller ensures

i) Constant switching frequency of the inverter

ii) Low sampling frequency

iii) Good dynamic response.

DTC - SVM with Fuzzy controller ensures

Along with the above merits the fuzzy controller further reduces the ripple in the current, flux and torque and also improves the dynamic response.

\section{REFERENCES}

[1]. L. Takahasi \& T. Noguchi, A New quick response and high efficiency strategy of induction motor; IAS 1985.p.495-502

[2]. M. Depenbrock, " Direct self control of inverter fed induction machine", IEEE Trans. Power Electronics.vol 3., No.4 , oct 1988.

[3]. I. Boldea, S.A. Nasar, " Torque vector control - A class of fast and robust torque speed and position digital controllers for electric drivers". Electrical machines and power systems. Vol.15, 1988, p. $135-147$

[4]. L. Zhong, M.F. Rahman, “ A Direct Torque controller for Permanent Magnet Synchronous Motor Drives". IEEE Trans. On energy conversion. Vol 14, no.3, sep 1999.

[5]. L. Zhong, M.F. Rahman, " Compaision of Torque response of the interior permanend magnet rotor and PWM current and direct torque control", IEEE.1999, P.1464 - 1470

[6]. L. Zhong, M.F. Rahman, K.W. Lim, “ A Direct Torque controlled interior permanent magnet sycnronous motor drive incorporating field weakening", IEEE 1997, P.67-74

[7]. P. Vas "Sensorless Vector and Direct Torque Control", oxford, uk, oxford university. Press 1998.

[8]. M. P Kazmierkowski, H. Tunia, “ Automatic control of converter fed drives". Amsterdam, the Netherlands : Elsevier, 1994

[9]. M. Fu, L. Xu, “ A novel sensor less control technique for PMSM using digital signal processor”. Neacon. 1997, Dayton, ohio, july, p. 14-17

[10]. M. Fu, L. Xu, "A Sensorless direct torque control technique for PMSM motors, IEEE. 1999, p.159-164.

\section{BIOGRAPHIES}

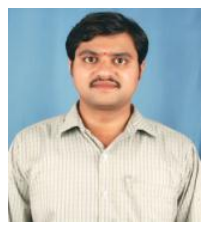

T. Ramasastryborn in 1981 in India. He received B.Tech degree in Electrical \& Electronics Engineering from JNTU, India in 2003 and M.Tech degree from JNTUH in Power Electronics in 2011. His research interest includes Electrical drives, Power Electronic converters. Currently he is working as Assistant Professor in the Department of Electrical and Electronics Engg., Anil Neerukonda Institute of Technology \&Sciences, Andhra University, India.

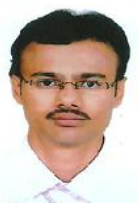

S.Harish received B.Tech degree in Electrical \& Electronics Engineering from Acharya Nagarjuna University, India in 2009 and M.Tech degree from Manipal University in Power Electronic Systems \& Control, in 2011. His research interest includes Applications of Power Electronics to Power Systems, FACTS, HVDC and Power System Stability \& Analysis. Currently he is working as Assistant Professor in the Department of Electrical and Electronics Engg., Anil Neerukonda Institute of Technology \& Sciences, Andhra University, India.

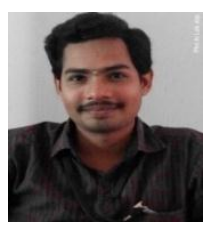

M.Sudheer Kumar received the B.Tech degree in EEE from from JNTUK, Kakinada, India in 2008. He has completed M.E (Power Electronic Drives and Control) in the department of EEE, A.U, Visakhapatnam, AP, and India in 2012. His research interests include Large scale system modelling \& design and Advanced control systems. Currently he is working as Assistant Professor in the Department of EEE., Anil Neerukonda Institute of Technology \& Sciences, Andhra University, India 